This is an Accepted Manuscript of an article published by Taylor \& Francis in 'Advances in School Mental Health Promotion' on 2015-11-30, available online: https://www.tandfonline.com/10.1080/1754730x.2015.1110494.

\title{
Pilot evaluation of the feasibility and acceptability of StressOFF Strategies: a single-session school-based stress management program for adolescents
}

\begin{abstract}
The present study reports the pilot evaluation of the feasibility and acceptability of StressOFF Strategies, a single-session (45 min) adolescent-targeted, school-based psychoeducational program, which introduces cognitive behavioral techniques and mindfulnessbased techniques. Five hundred and sixty-five Grade 9 students (57\% female; $M_{\mathrm{age}}=14.97, S D=$ 0.36) completed self-report measures of stress, current stress management use, satisfaction with program, understanding of and future willingness to use strategies taught. Pre- intervention, $35.04 \%$ of participants reported a moderate-high overall stress level. Furthermore, all participants initially reported limited strategy use with distraction as the most common strategy (68.89\%). Post-intervention, $88.67 \%$ of participants rated the program as good to excellent with over $87 \%$ of participants reporting understanding strategies quite well to very well, and $76-87 \%$ of participants indicating high levels of willingness to use each strategy. Females reported high levels of stress, greater satisfaction with the program, and better understanding and willingness to use strategies. Implications for schools are discussed.
\end{abstract}

Adolescence is characterized as a period of transition with accompanying biological, social and psychological changes (Hankin, Mermelstein, \& Roesch, 2007). These changes yield newfound sources of stress for adolescents, calling on the need for the acquisition of new psychological adaptations (Byrne, Davenport, \& Mazanov, 2007; Moksnes, Byrne, Mazanov, \& Espnes, 2010). Stress in adolescents is derived from both normative stressors (e.g. puberty, school transition, increased academic demands) and non-normative stressors (e.g. divorce, family financial issues) (McNamara, 2000; Suldo, Shaunessy, \& Hardesty, 2008). 
This is an Accepted Manuscript of an article published by Taylor \& Francis in 'Advances in School Mental Health Promotion' on 2015-11-30, available online: https://www.tandfonline.com/10.1080/1754730x.2015.1110494.

When an adolescent's stress level exceeds what he or she is capable of coping with, he or she may begin to exhibit visible, acute symptoms which generally fall into three categories: cognitive (e.g. difficulty concentrating, academic difficulties), physiological (e.g. somatic complaints), and behavioral (e.g. mood swings, changes in sleep patterns) (Washington, 2009). In addition, when children have inadequate coping skills and are confronting difficult stressors, the effects may become more long term, negatively impacting physical health, which may lead to compromised immunity and a higher risk of developing illness (Rabin, 1999; Washington, 2009). Furthermore, difficulty coping with stress that is left unaddressed may have detrimental effects on an adolescent's mental health and may also impair the functions that are vital for effective learning (Arnsten, 1998; Metz et al., 2013).

A recent survey by the American Psychological Association (APA, 2014), 'Stress in America: Are Teens Adopting Adults' Stress Habits?' states that during the school year, 27\% of adolescents report high levels of stress ( $8-10$ on a 10 -point scale). The most commonly reported stressor is school, with $83 \%$ of adolescents maintaining that academic-related stress is the most difficult stressor to cope with, impacting grades, time management, and at times, relationships with peers and family. Other commonly reported sources of stress include worries about the future $(69 \%)$ and family financial concerns (65\%). However, despite its impact, most adolescents do not set aside time to manage their stress even though a majority (51\%) recognize the importance of practicing stress management. The APA survey also found that females report more stress than males. Consistent with previous literature, females frequently report greater levels of perceived stress compared to males (e.g. Galaif, Sussmann, Chou, \& Wills, 2003; Hampel \& Petermann, 2006) and experience more interpersonal stressors (e.g. peer relationships; Hankin, Mermelstein, \& Roesch, 2007). 
This is an Accepted Manuscript of an article published by Taylor \& Francis in 'Advances in School Mental Health Promotion' on 2015-11-30, available online: https://www.tandfonline.com/10.1080/1754730x.2015.1110494.

Nonetheless, adolescent stress, for males and females alike, is a risk factor for negative outcomes, such as anxiety disorders (Byrne, Davenport, \& Mazanov, 2007; Rudolph, 2002), depression (Auerbach, Bigda-Peyton, Eberhart, Webb, \& Ho, 2011; Waaktaar, Borge Helmen, Fundinsgrud, Christie, \& Torgersen, 2004), substance abuse (Galaif, Sussan, Chou, \& Wills, 2003), and academic underachievement (Schmeelk-Cone \& Zimmerman, 2003); however, the ability to cope with stress is strongly related to healthy development, psychological adjustment, and academic performance (Compas, Connor-Smith, Saltzman, Thomsen, \& Wadsworth, 2001; Eisenberg et al., 2010; Metz et al., 2013).

Unfortunately, half of adolescents (50\%) have difficulty coping with stress, with females reporting more coping difficulty than males (APA, 2014). Commonly reported coping behaviors include playing video games (46\%), going online (43\%), physical activity (37\%), watching television or movies (36\%), and playing sports (28\%) (APA, 2014). Although adolescents report adaptive coping behaviors such as physical activity and distraction (e.g. watching television or movies), adolescents are also engaging in high-risk behaviors to manage stress, such as smoking, drug abuse, risky sexual behavior, and non-suicidal self-injury (Rew, 2005). Fortunately, many adolescents $(43 \%)$ are open to the idea of receiving support from mental health professionals to manage their stress, yet only $5 \%$ have consulted with a mental health professional for stress management (APA, 2014).

With adolescent stress on the rise (APA, 2014), there is some suggestion that one's capacity to employ effective coping strategies may mitigate the impact of stress on adjustment and psychopathology (Compas et al., 2001). Adaptive coping falls into two categories as put forth by Folkman and Lazarus (1980): (1) problem-focused coping (e.g. altering one's environment, seeking external resources) and (2) emotion-focused coping (e.g. cognitive 
This is an Accepted Manuscript of an article published by Taylor \& Francis in 'Advances in School Mental Health Promotion' on 2015-11-30, available online: https://www.tandfonline.com/10.1080/1754730x.2015.1110494.

restructuring, emotional regulation and employing selective attention) (Pincus \& Friedman, 2004).

Coping style may vary according to age. There is evidence that problem-focused strategies are generally used by young children while emotion-focused strategies are acquired in late childhood and early adolescence (Pincus \& Friedmann, 2004). Hampel and Petermann's (2005) study supported this assumption, claiming that problem-based strategies 0 (e.g. support seeking and positive self-instruction) are developed in early childhood, yet taper off in early adolescence. The researchers found that the use of distraction or reaction as a coping strategy decreased with age whereas maladaptive coping strategies (e.g. rumination and aggression) increased from childhood to adolescence - a finding that sheds light on the insufficient coping capacity of youth in early to middle adolescence.

\section{School-based stress management}

Given the decrease in adaptive coping and increase in maladaptive coping strategies in middle adolescent years (Frydenberg \& Lewis, 2000; Hampel \& Petermann, 2005, 2006), there is a need for adolescent-targeted programs to promote adaptive coping through the teaching of effective coping skills (Frydenberg \& Lewis, 2000). The school has been proposed as an appropriate site to implement such programs (Lock \& Barrett, 2003), due in part to the frequency in which youth in this age group are reporting school-related stressors (APA, 2014). Indeed, the school provides favorable conditions in which stress and stress-related conditions can be addressed in order to prevent the onset or worsening of such difficulties. First, the school provides an avenue in which a large number of young people can be reached, as the vast majority of youth attend public and private schools (Huberty, 2012). Moreover, in such a setting, access to programs is maximized as common barriers to interventions (e.g. costs and transportation) are 
This is an Accepted Manuscript of an article published by Taylor \& Francis in 'Advances in School Mental Health Promotion' on 2015-11-30, available online: https://www.tandfonline.com/10.1080/1754730x.2015.1110494.

reduced (Lock \& Barrett, 2003). In addition to increased access to care, providing an intervention to youth where they typically experience their greatest difficulties allows them to apply what they have learned to real-world situations (Fisher, Masia-Warner, \& Klein, 2004).

\section{School-based cognitive behavioral stress management programs}

Currently, cognitive behavioral therapy (CBT) is the most extensively practiced method in school-based stress management prevention. CBT is an evidence-based, symptom-focused approach rooted in both cognitive therapy and behavior therapy (Rachman, 1997). CBT is built around the theoretical assumption that an individual's cognitions are largely influenced by previous experiences. Previous experiences may contribute to the development of schemas, which may influence the way individuals interpret future experiences (Beck, Rush, Shaw, \& Emery, 1979). Therefore, a crucial component of CBT is to identify and correct distorted thinking through a process known as cognitive restructuring (Beck, Emery, \& Greenberg, 1985). Nevertheless, CBT is not limited to cognitive modification (Hofmann \& Asmundson, 2008); rather, this approach endorses both problem- and emotion-focused coping through the teaching of cognitive and behavioral strategies deemed necessary to effect change (Kendall, 2012).

To date, several school-based cognitive behavioral stress management programs have been evaluated and demonstrate positive effects on students' stress and coping behaviors. De Anda and colleagues (1998) evaluated the effectiveness of a 10-week cognitive behavioral stress management program for middle school adolescents based on an earlier, abridged program that had been developed for and implemented with pregnant teenagers (1990). In similar studies, Barrett and Turner (2001) and Lowry-Webster, Barrett, and Dadds (2001) evaluated the effectiveness of FRIENDS (Barrett, 2005), a 10-week universal school-based, cognitive behavioral intervention targeting anxiety and depression. Most recently, Hampel, Meier and 
This is an Accepted Manuscript of an article published by Taylor \& Francis in 'Advances in School Mental Health Promotion' on 2015-11-30, available online: https://www.tandfonline.com/10.1080/1754730x.2015.1110494.

Kümmel (2008) evaluated Anti-Stress Training (AST; Hampel \& Petermann, 2003), a six-week school-based cognitive behavioral stress management program for early and middle adolescents. All mentioned programs contain similar components that may contribute to their success:

psychoeducation (stress and coping), cognitive skills (e.g. positive self- talk), physiological skills (e.g. muscle relaxation), and behavioral skills (e.g. problem solving). However, a possible limitation of these studies is that they exclusively examined the effectiveness of the intervention without taking into account feasibility or student acceptability of the mentioned programs.

\section{Mindfulness-based programs targeting mental health in schools}

Although CBT maintains its title as the dominant approach for stress management and prevention in both an individual therapeutic context and in the school setting, mindful- nessbased interventions have recently grown in popularity and are consistently receiving support as an effective intervention approach for stress (vøllestad, Nielsen, \& Nielsen, 2011). Mindfulness has its roots in Eastern meditation practice, but has become integrated into numerous programs, such as mindfulness-based stress reduction (MBSR; Kabat-Zinn, 1990), mindfulness-based cognitive therapy (MBCT; Segal, Williams, \& Teasdale, 2002), and dialectical behavior therapy (DBT; Linehan, 1993).

A primary goal of mindfulness-based interventions is to increase awareness of the present moment with an open and accepting attitude that welcomes all experiences, both positive and negative (Hayes, 2004; Kabat-Zinn, 1990). Efforts to rid oneself of unwanted thoughts, feelings, and sensations may in fact have a counter-therapeutic effect; instead, individuals are encouraged to adopt a non-judgmental, present-centered attitude so they can move toward valued goals in spite of the unpleasant thoughts and feelings experienced in the process (Forman, Herbert, Moitra, Yeomans, \& Geller, 2007). Mindfulness and cognitive behavioral therapy are sometimes 
This is an Accepted Manuscript of an article published by Taylor \& Francis in 'Advances in School Mental Health Promotion' on 2015-11-30, available online: https://www.tandfonline.com/10.1080/1754730x.2015.1110494.

viewed as conflicting approaches; however, both approaches endorse fostering an awareness of thoughts as 'mind events' that can be examined, which creates distance and objectivity.

Recently, there has been an increase in mindfulness-based programs that target stress management and well-being in schools. Broderick and Metz (2009) and Metz and colleagues (2013) evaluated the effectiveness of Learning to BREATHE, a six-week school-based program for adolescents designed to cultivate students' development of emotion regulation and well-being through the practice of mindfulness. In addition to the program's effectiveness, both studies assessed the program's acceptability, and found a high level of social validity and acceptability of the Learning to BREATHE program. Similarly, Schonert-Reichel and Lawlor (2010) evaluated Mindfulness Education (ME), a 10-week school-based program for pre- and early adolescents developed to promote social and emotional competence and positive emotions through mindfulness attention training. Students who participated in the mindfulness-based programs demonstrated greater emotion regulation skills and awareness of feelings. The teachers who participated in the program experienced ease delivering the 'core' mindfulness attention exercises. They also reported that students frequently reminded them to stop the regular classroom instruction in order to practice their 'mindful breathing' lesson. The components shared by the Learning to BREATHE program and ME programs include body awareness, focusing on the breath, paying attention to thoughts and feelings, and managing negative thoughts and feelings.

Overall, findings from the cognitive behavioral and mindfulness school-based programs suggest that youth can be taught coping skills to help effectively manage stress, and in the case of the mindfulness programs reviewed, these programs are deemed highly acceptable by students and teachers alike (e.g. Schonert-Reichel \& Lawlor, 2010). Although cognitive behavioral 
This is an Accepted Manuscript of an article published by Taylor \& Francis in 'Advances in School Mental Health Promotion' on 2015-11-30, available online: https://www.tandfonline.com/10.1080/1754730x.2015.1110494.

techniques remain the most extensively researched and practiced approaches for stress management, mindfulness-based interventions are gaining increased support for the prevention of stress-related difficulties (e.g. Broderick \& Metz, 2009; Metz et al., 2013; Schonert-Reichel \& Lawlor, 2010); however, to the authors' knowledge, no studies have attempted to introduce both cognitive behavioral and mindfulness-based techniques in a single-session school-based stress management program for adolescents.

Single-session interventions with adults have been found to be effective in reducing anxiety (Amir, Weber, Beard, Bomyea, \& Taylor, 2008), depression (Danitz \& Orsillo, 2014), stress (Nosaka \& Okamura, 2015), and have succeeded in increasing knowledge about stress and coping (Shimazu, Umanodan, \& Schaufeli, 2006). Clearly, single-session interventions have potential merit for use with adolescents, particularly in the school setting in light of school curriculum constraints. Existing programs that are school-based and adolescent-targeted are lengthy and require time which schools are often lacking (Fridrici \& Lohaus, 2009). The provision of these programs also demands additional personnel resources and special training, which poses added barriers to their implementation (Evans \& Weist, 2004).

Thus, the present study reports the evaluation of the feasibility, acceptability, and perceived usefulness of StressOFF Strategies (Shapiro \& Heath, 2013), a single-session (45 min) adolescent-targeted, school-based psychoeducational program which introduces cognitive behavioral techniques (e.g. cognitive restructuring, progressive muscle relaxation) and mindfulness-based techniques (e.g. present-moment awareness and acceptance). Specific objectives were (a) to assess students' pre-program reports of stress, knowledge of stress management, including previous stress management instruction, and frequency of use of stress management techniques, (b) to evaluate the feasibility and acceptability of StressOFF Strategies by examining 
This is an Accepted Manuscript of an article published by Taylor \& Francis in 'Advances in School Mental Health Promotion' on 2015-11-30, available online: https://www.tandfonline.com/10.1080/1754730x.2015.1110494.

participants' post-program reports of learning, ratings of the program, understanding of taught stress management techniques, and willingness to use the techniques, and (c) to investigate the role of gender in reports of stress and response to the program.

\section{Method}

\section{Participants}

The overall sample for this study consists of 565 Grade 9 students $(57.52 \%$ female, 42.48\% male). Participants ranged from 14 to 16 years of age $(M=14.97, S D=0.36)$. Participants were drawn from 52 Grade 9 public education classrooms in ten secondary schools in and around Montreal, Quebec, Canada. The schools were categorized as low socioeconomic status (SES) urban (10\%), middle SES urban (30\%), middle SES suburban (40\%) to high SES independent fee-based (20\%). The 52 Grade 9 public education classrooms had been involved in a longitudinal three-year study on stress and coping during the transition to secondary school. While only a portion of Grade 9 students completed the three-year study, all Grade 9 students $(N$ $=1313)$ were offered and completed a workshop on effective stress management. Forty-three percent of these students returned signed student assent and parent consent forms and were included in the current study $(n=565)$.

\section{Program summary}

StressOFF Strategies (Shapiro \& Heath, 2013) is a 45-min, adolescent-targeted schoolbased stress management program that aims to equip teenagers with the necessary coping skills to effectively manage stress. The development of the program content was guided by a detailed review of literature and evidence in the area of adolescent stress management. The program consists of four key components: (a) Decreasing stigma (b) Psychoeducation (c) Coping skills 
This is an Accepted Manuscript of an article published by Taylor \& Francis in 'Advances in School Mental Health Promotion' on 2015-11-30, available online: https://www.tandfonline.com/10.1080/1754730x.2015.1110494.

(cognitive behavioral and mindfulness-based techniques), and (d) Follow-up (pamphlet and online resources).

\section{Decreasing stigma}

The program begins and ends with a video of a real student who shares his experience with stress in high school. In this video, students are spoken to directly with understanding of their struggles with stress and reassurance that there are coping strategies available to help manage their stress. Additionally, examples of celebrities are carefully chosen to illustrate reallife scenarios of cognitive, physiological, and behavioral manifestations of stress. The judicious incorporation of celebrity examples also demonstrates to students that difficulty handling stress is universal and spares no one, not even the rich and famous. To further decrease stigma, the presenters share real examples of their own struggles with stress and coping throughout the presentation. These examples are agreed upon in advance with the StressOFF Strategies training team to ensure some similarity across presenters and developmental appropriateness for teens.

\section{Psychoeducation}

In the psychoeducation component of the program, students are provided with a definition of stress, including its adaptive and maladaptive components. Cognitive, physiological, and behavioral manifestations of stress are examined. Students are then asked to fill out a stress profile, allowing them to identify the cognitive, physiological, and behavioral expressions of their own stress. This profile helps students better understand how their stress expresses itself, in order to tailor their coping responses accordingly (which are addressed in the second half of the program). All definitions provided are developmentally appropriate and make 
This is an Accepted Manuscript of an article published by Taylor \& Francis in 'Advances in School Mental Health Promotion' on 2015-11-30, available online: https://www.tandfonline.com/10.1080/1754730x.2015.1110494.

use of interactive diagrams, images, and animations to help facilitate student understanding of difficult concepts.

\section{Coping skills}

The strategies from CBT and mindfulness that were selected for the program target the cognitive, physiological, and behavioral signs of stress. Together they form the acronym STRESS- for Stop, Thought challenge, RElaxation, Self-observer, Support and better choices which can make it easier for students to recall and access the strategies.

\section{Cognitive strategy: stop and thought challenge}

Students are presented with a negative thought, such as 'I'm a complete failure.' The facilitator proceeds to tell students when they experience a negative thought to first stop and take a deep breath. The second step is to challenge the thought (thought restructuring), by asking oneself: If a friend came up to me and said this same thought, would I agree with this statement? Students in turn understand that they should challenge a negative thought in the same way they would if a friend were in the same situation: with compassion and understanding.

\section{Physiological strategy: relaxation}

Students are introduced to an inconspicuous form of relaxation that can be used anywhere and at any time: progressive muscle relaxation (PMR). PMR reduces physiological stress by progressively tensing and then relaxing each muscle group in the body. To illustrate the physiological benefits of PMR, the facilitator guides students through a 3-min exercise while sitting at their desks. Students have the option of keeping their eyes open or closed.

\section{Mindfulness strategy: self-observer}


This is an Accepted Manuscript of an article published by Taylor \& Francis in 'Advances in School Mental Health Promotion' on 2015-11-30, available online: https://www.tandfonline.com/10.1080/1754730x.2015.1110494.

With the self-observer strategy, students are taught how to become aware of the present moment without judging: just 'observing' (mindfulness). The self-observer is also an inconspicuous strategy that can be employed at any time. It is particularly effective as a grounding strategy when experiencing overwhelming thoughts and feelings. To illustrate the strategy, the facilitator guides students through 'The Chair' exercise, a step-by-step self-observer activity, which helps students focus on their senses (e.g. the feeling of the chair beneath them, the sounds that come to their ears), and finally turning their observation to their breath, without trying to change or alter anything. Emphasis is on focusing on the present moment experience; when a thought comes up they are encouraged to note, 'there is a thought,' and then gently turn their focus back to the feeling of the chair, the sounds coming to their ears, or to the physical sensations of their breath.

\section{Behavioral strategy: support and better choices}

Students are encouraged to reflect on the choices they make when feeling stressed and whether these choices may induce further stress. Healthy lifestyle choices, such as eating well, getting enough sleep, and exercising routinely are encouraged. Furthermore, students are urged to access their support network or to seek help when experiencing difficulty managing their stress.

\section{Follow up}

Following the program, students are given a pamphlet that outlines the information provided in the workshop, including the four strategies. Finally, students are directed to the StressOFF Strategies webpage, where students can find program resources and access links to other helpful stress management resources. 
This is an Accepted Manuscript of an article published by Taylor \& Francis in 'Advances in School Mental Health Promotion' on 2015-11-30, available online: https://www.tandfonline.com/10.1080/1754730x.2015.1110494.

\section{Procedure}

Five graduate students in Educational Psychology were trained to deliver the StressOFF Strategies program. Program training, which was led by the primary researchers, consisted of a $1.5 \mathrm{~h}$ training session during which the graduate students were given a detailed script of the stress management program and the accompanying PowerPoint/video presentation. The script provided step-by-step instructions in order to facilitate training and ensure treatment integrity. The training also included simulated exercises of the strategies taught (e.g. progressive muscle relaxation and present-moment awareness and acceptance).

Following university ethics approval, school board and school approval, school personnel were provided with a package containing an oral script to be read to students describing the study as well as consent forms to be distributed. Arrangements were then made with school personnel for graduate students to deliver the program and to carry out data collec- tion. Both the program and data collection were administered and completed within one classroom period. The workshop took place in classes of 30-35 students in their classrooms, which were either equipped with a Smart Board or a screen and LCD projector. The trained graduate students arrived in the classrooms and provided each student who had parental consent with an envelope that contained the student assent form and the pre-program and post-program questionnaires. To ensure that participants felt comfortable in the confidenti- ality of their evaluations, a separate research assistant was designated to collect evaluations, which were in sealable envelopes.

\section{Measures}

\section{Pre-program measures}

\section{Perceived stress}


This is an Accepted Manuscript of an article published by Taylor \& Francis in 'Advances in School Mental Health Promotion' on 2015-11-30, available online: https://www.tandfonline.com/10.1080/1754730x.2015.1110494.

Perceived stress was assessed by 10 items on the Perceived Stress Scale (PSS; Cohen, Kessler, \& Underwood Gordon, 1995), adapted by the researchers. The PSS is a widely used measure of overall stress in which students are asked to report how often they had been burdened by feelings of uncontrollability, unpredictability, and inability to cope with stressors in the previous month. Items are evaluated on a five-point Likert scale, ranging from 'never' $(0)$ to 'very often' (4). The researchers adapted the wording of the items to facilitate summation for students, who were asked to calculate their own stress score, which was referred to in the program. The minimum stress score is 0 while the maximum score is 40 . The researchers assigned stress scores to categories as follows: 0-20 (mild), 21-30 (moderate), and 31-40 (high). The PSS has good internal consistency $(\alpha=.85)$, and test-re-test reliability ranging from .75 to .86 (Cohen, Kamarch, \& Mermelstein, 1983). Furthermore, in the present study, it was found to have high internal consistency of $\alpha=.93$.

\section{Knowledge of stress management and use of stress management techniques}

Before the program, participants were asked to rate their knowledge of stress management on a Likert-type four-point scale ranging from 'nothing at all' (0) to 'a lot' (4). Participants were also asked whether they used stress management techniques and to identify their strategies of choice from a list of possible stress management techniques or identify other techniques. In addition, they were asked if they had received previous stress management instruction. They were also asked to rate their interest in learning about stress management on a Likert-type four-point scale ranging from'not at all interested'(0) to 'very interested'(3).

\section{Post-program measures}


This is an Accepted Manuscript of an article published by Taylor \& Francis in 'Advances in School Mental Health Promotion' on 2015-11-30, available online: https://www.tandfonline.com/10.1080/1754730x.2015.1110494.

Acquired knowledge of stress management, understanding and willingness to use stress management techniques

Following the program, items were structured to assess participant's perceived new knowledge of stress management. Participants were asked to rate how much they learned after participating in the program on a Likert-type four-point scale ranging from 'nothing' to 'a lot'. They were also asked to rate the StressOFF Strategies program on a Likert-type four-point scale ranging from 'poor' (1) to 'excellent' (4).

Participants also were asked to indicate their understanding of specific stress management techniques taught in StressOFF Strategies (e.g. thought challenge, muscle relaxation, selfobserver, and support and better choices) on a Likert-type scale ranging from 'not very well' (1) to 'very well' (3), with a further choice of 'already knew' (4). Finally, participants were asked to rate their willingness to use the strategies learned in the program (e.g. thought challenge, muscle relaxation, self-observer, support, and better choices) on a Likert-type scale ranging from 'never: I don't like this technique' (1) to 'always' (4). Participants who did not identify a need for stress management were given the option to choose 'never: I don't need to use stress-management' (0).

\section{Results}

\section{Pre-program reports}

\section{Perceived stress and gender differences}

Prior to the program, $35.04 \%$ of participants reported moderate to high levels of stress. The average overall perceived stress level reported by Grade 9 students was $17.38(S D=8.93)$, which is categorized by the researchers as 'mild.'There was a significant relationship between 
This is an Accepted Manuscript of an article published by Taylor \& Francis in 'Advances in School Mental Health Promotion' on 2015-11-30, available online: https://www.tandfonline.com/10.1080/1754730x.2015.1110494.

gender and perceived stress level, with females reporting a higher overall stress level $(M=19.88$, $S D=8.67)$ than their male peers $(M=13.99, S D=8.14), t(563)=-8.19, p<.001, d=0.70$.

\section{Knowledge of stress management, previous stress management instruction and gender differences}

Overall, $72.74 \%$ of students answered 'nothing at all' to 'a bit' when asked about previous knowledge about stress management, with no significant gender differences (Table 1). Students were also asked whether they received previous stress management training before attending the StressOFF Strategies program. Only $25.13 \%$ of participants reported that they had had any previous stress management training, with no significant difference between male and female reports.

Interest in learning about stress management, frequency of using stress management techniques, previous stress management use, and gender differences

Students were asked to rate their interest in learning about stress management. Overall, $62.48 \%$ of students reported being 'quite interested' to 'very interested' in learning about stress and stress management, and females reported significantly more interest in learning about stress than males (Table 1). Students were asked about their frequency of using stress management techniques. Overall, $66.02 \%$ of students reported using stress management techniques ‘sometimes'to'very often,' and females reported using stress management tech- niques more than males (Table 1). The main strategies used previously were distraction (68.89\%), taking a deep breath (44.25\%) and talking to a friend (37.52\%). Chi square analyses were used to investigate gender differences in the total number of strategies endorsed (e.g. 0-8). Results demonstrated that there was a different pattern of frequency of endorsement of previous 
This is an Accepted Manuscript of an article published by Taylor \& Francis in 'Advances in School Mental Health Promotion' on 2015-11-30, available online: https://www.tandfonline.com/10.1080/1754730x.2015.1110494.

strategies such that females were prone to a greater variety of coping strategies compared to males, $\chi^{2}(8)=56.18, p<.001, \phi=.32$. Specifically, $84.32 \%$ of females endorsed using 4 or fewer strategies, while $92.91 \%$ of males reported using 4 or fewer strategies; $15.7 \%$ of females reported using 5-8 strategies compared to $7.08 \%$ of males.

\section{Post-program reports}

Following the program when asked how much they had learned in StressOFF Strategies, a majority $(86.55 \%)$ of students reported that they had learned a medium amount to a lot about stress management, with no significant gender differences on these scores (Table 2).

Furthermore, $88.67 \%$ of participants rated the program as good to excellent, with no gender differences in these reports (Table 2).

In addition, in the post-program evaluations, students were asked to rate their understanding of specific stress management techniques taught in the program; these results are shared in Table 2. Responses indicated that $92.23 \%$ of students felt that they understood the 'Stop, Thought Challenge' strategy quite well to very well, with females reporting significantly higher understanding than males for this strategy. Similarly, $97.71 \%$ of students reported that they understood the 'Muscle Relaxation' strategy quite well to very well and again females reporting better understanding of this strategy than their male counterparts. However, although similar levels of understanding were found for the 'Self-Observer' strategy, as $87.83 \%$ of students indicated that they understood this strategy quite well to very well, for this strategy there were no significant gender differences. For 'Support and Better Choices,' there were also high levels of understanding with $93.62 \%$ of students reporting they understood the strategy quite well to very well, and once again, females indicated significantly better understanding than males. Finally, 8$14 \%$ of students indicated they already knew the strategies taught. 
This is an Accepted Manuscript of an article published by Taylor \& Francis in 'Advances in School Mental Health Promotion' on 2015-11-30, available online: https://www.tandfonline.com/10.1080/1754730x.2015.1110494.

In the post-StressOFF Strategies evaluation, students were asked to rate their willingness to use the strategies taught in the program in the future, these results are shared in Table 2.

Overall, students indicated high levels of willingness to use the strategies in the future, ranging from a low of $76.24 \%$ of them indicating a willingness to use the Self-Observer strategy 'sometimes'to 'always' to $87.10 \%$ indicating'sometimes'to 'always' for willingness to use 'Muscle Relaxation.'The strategies ‘Stop, Thought Challenge' and 'Support and Better Choices' fell in between with 78.81 and $85.14 \%$ of students, respectively, indicating willingness to use these techniques in the future. Consistently, as indicated in Table 2, females reported greater willingness to use all of the strategies relative to their male peers. Finally, 5-8\% of students indicated that they do not need to use stress management.

\section{Discussion}

The purpose of this study was to evaluate the feasibility, acceptability, and perceived usefulness of StressOFF Strategies, a single-session (45 min) adolescent-targeted, school-based stress-management program. Specific objectives were (a) to assess students' pre-program reports of stress, knowledge of stress management, including previous stress management instruction, and frequency of use of previous stress management techniques, (b) to evaluate the feasibility and acceptability of StressOFF Strategies by examining participants'post-pro- gram reports of learning, ratings of the program, understanding of taught stress management techniques, and willingness to use the techniques, and (c) to investigate the role of gender in reports of stress and response to the program.

The first aim of the study was to report students' pre-program stress and knowledge of stress management, including previous stress management instruction, and frequency of use of previous stress management techniques. As indicated in the results, the majority of participants 
This is an Accepted Manuscript of an article published by Taylor \& Francis in 'Advances in School Mental Health Promotion' on 2015-11-30, available online: https://www.tandfonline.com/10.1080/1754730x.2015.1110494.

reported a moderate overall stress level, limited previous knowledge about stress and stress management, and frequent previous use of general or non-specific stress management techniques (e.g. distraction, taking a deep breath, talking to a friend); however, participants also reported a high interest in learning about stress and furthering their knowledge of effective stress management skills. Despite an expressed interest by the majority of the students, there was an absence of previous information and training in the area. Consistent with the literature, adolescents reported significant levels of stress (APA, 2014); however, the current results revealed that although youth are receptive to learning stress management techniques and are open to stress management instruction, they are not receiving such instruction. Indeed, adolescents are endorsing multiple non-specific stress-management strategies that are not the most effective. Given the previous research on the effectiveness and acceptability of adolescenttargeted school-based stress management programs (e.g. Broderick \& Metz, 2009; de Anda et al., 1990; Hampel \& Petermann, 2003) together with the present findings, there is a clear need for schools to provide more stress management programs, particularly in light of the fact that poor coping often surfaces in early to middle adolescence (Frydenberg \& Lewis, 2000; Hampel \& Petermann, 2005, 2006).

The second aim of the study was to evaluate the feasibility and acceptability of the program by examining participants' post-program reports of understanding stress management and willingness to use the taught techniques. As indicated in the results, the participants' response to a single-session intervention was overwhelmingly positive, as the majority of the participants reported that they learned 'a medium amount' to 'a lot' about stress management, and rated the program highly. The existing lengthy programs for youth (e.g. Learning to BREATHE, Mindfulness Education) have demonstrated high acceptability and/or social validity to the 
This is an Accepted Manuscript of an article published by Taylor \& Francis in 'Advances in School Mental Health Promotion' on 2015-11-30, available online: https://www.tandfonline.com/10.1080/1754730x.2015.1110494.

participants (e.g. Metz et al., 2013; Schonert-Reichel \& Lawlor, 2010); however, the current single-session stress management program had a comparable level of acceptability, suggesting that students find this approach acceptable and are receptive to a more time limited program. This high acceptability of a limited single-session program, which does not interfere with curriculum demands, supports the notion that a program such as this would be well received by students in schools. In combination with the students'desire for stress management instruction, these results provide evidence for the appeal of and feasibility of such a program.

Following the program, when participants were asked to rate their future willingness to use the specific strategies taught, the students reported overwhelmingly high levels of willingness to use the stress management strategies. Although the strategies taught were not the same strategies that the students had endorsed prior to the program, their high willingness to use these strategies in the future suggests that they are receptive to learning new, evidence-based techniques. Interestingly, this finding lends support to previous findings that demonstrate that students are open to using alternative and unfamiliar strategies for stress management use, such as mindfulness-based techniques, which have typically been included in other programs in a lengthier format (Broderick \& Metz, 2009). Furthermore, substantial reports of willingness to use'Muscle Relaxation'and'Support and Better Choices' emphasize students' receptivity to a combination of physiological and behavioral strategies, adding to existing literature, which has found that incorporating effective interventions that target the cognitive, physiological, and behavioral processes associated with stress through coping skills instruction in each domain (e.g. Barrett, 2005).

The third aim of the study was to examine gender differences in reported stress and response to the program. A consistent pattern of gender differences across every aspect of the 
This is an Accepted Manuscript of an article published by Taylor \& Francis in 'Advances in School Mental Health Promotion' on 2015-11-30, available online: https://www.tandfonline.com/10.1080/1754730x.2015.1110494.

study was found. Specifically, pre-program, females reported higher overall stress, using greater numbers of stress management techniques, more frequent previous stress management technique use, higher interest in learning about stress management. Post-program, females endorsed greater understanding of and willingness to use the strategies taught in the future compared to male participants. These findings are compatible with previous research demonstrating that female adolescents reported higher levels of perceived stress than their male peers (e.g. Galaif, Sussmann, Chou, \& Wills, 2003; Hampel \& Petermann, 2006). In general, research findings tended to indicate that compared to males, females experienced more interpersonal stressors (e.g. peer relationships; Hankin, Mermelstein, \& Roesch, 2007), and thus higher levels of overall stress. In addition to females indicating higher stress and use of a higher number of stress management techniques when compared to males, the specific techniques females reported using are not considered to be the most effective for stress management. Furthermore, females' higher reports of interest in learning about novel techniques highlight the need for providing support, particularly for females, during the stressful period of adolescence. These findings suggest that females are more willing than males to identify their stress and are more open than males to engaging in stress management activities, which suggests that they may be more likely than males to access mental health services in the schools. However, caution must be used in interpreting these gender differences as the effect sizes were frequently small, suggesting that while there is a consistent pattern of females reporting more stress as well as more interest and stress management technique use when compared to males, the overall difference between males and females may not be large and replication of findings is needed.

The results of this evaluation study of the StressOFF Strategies program provide encouraging support for the application of a single-session, universal, adolescent-targeted stress 
This is an Accepted Manuscript of an article published by Taylor \& Francis in 'Advances in School Mental Health Promotion' on 2015-11-30, available online: https://www.tandfonline.com/10.1080/1754730x.2015.1110494.

management program in a high school setting. Results suggest that students are interested in learning about stress management and yet few have had any training in stress management. Furthermore, even a single session resulted in excellent perceived understanding and willingness to use stress management techniques, including cognitive behavioral and mindfulness techniques. Most encouraging are students' high ratings of satisfaction with the program, students' high rates of understanding strategies taught in the program, and students' high reported likelihood of using strategies learned in the program.

\section{Limitations and final conclusions}

Some limitations must be taken into account when considering the overall feasibility, acceptability and perceived usefulness of the program. Data collection and program delivery were both executed within the time frame of one-class period (e.g. 45-60 min), which made the assessment of the program very brief. Second, although students reported a willingness to use strategies, it would be of interest to complete a follow-up assessment of actual use of strategies and potential benefits in terms of lowered stress. Ethnicity, presence of disability, and socioeconomic status were not directly measured in the current study; however, as indicated in the procedure section, schools included had students from a range of socioeconomic statuses and from different areas in and around the city.

Another possible limitation is that the pre- and post-test measures were composed of different sets of questions, and the pre-test measure did not include items on the students' previous knowledge of specific stress management strategies taught in the program (e.g. progressive muscle relaxation, self-observer). Although it would have been advantageous to have identical pre- and post-test measures, pilot testing of the measures revealed that adolescents were not familiar with the specific strategies that were being taught in the program; therefore, a 
This is an Accepted Manuscript of an article published by Taylor \& Francis in 'Advances in School Mental Health Promotion' on 2015-11-30, available online: https://www.tandfonline.com/10.1080/1754730x.2015.1110494.

checklist of possible strategies was included to determine students' previous knowledge and experience with stress management (e.g. which stress management techniques do you use?).

As noted earlier, given that the effect sizes for the gender differences were small, further replication of these findings is needed. Nevertheless, the consistent pattern of differences among females' and males' reports of stress, with females reporting more stress and overall interest and engagement in learning about stress management strategies, suggests that these findings may be meaningful.

Furthermore, the majority of students indicated that they know nothing at all about stress management; however, it is possible that some of the strategies from the Support and Better Choices section might have been covered in health class in their schools and not specifically referred to as 'stress management strategies.' Nevertheless, in discussions with educators and administrators in the schools where the StressOFF Strategies program was presented, educators and administrators acknowledged the fact that students had never received this type of information in their schools. Finally, the current program exposes students to cognitive behavioral and mindfulness based techniques in an introductory manner, which enables students to learn about these techniques in a limited capacity. Supplemental resources were provided for students to gain additional information and access to these techniques when desired.

The present study represents a first step in research evaluating the feasibility, acceptability, and perceived usefulness of a single-session, universal, adolescent-targeted schoolbased psychoeducational programs which introduce cognitive behavioral techniques (e.g. cognitive restructuring, progressive muscle relaxation) and mindfulness-based techniques (e.g. present-moment awareness and acceptance). Overall, our results demonstrate that adolescents report high levels of satisfaction, understanding, and willingness to use stress management 
This is an Accepted Manuscript of an article published by Taylor \& Francis in 'Advances in School Mental Health Promotion' on 2015-11-30, available online: https://www.tandfonline.com/10.1080/1754730x.2015.1110494.

strategies that are taught over the course of one-school period. This finding has tremendous implications for school personnel, who are often confronted with the dilemma of wanting to bring mental health initiatives to their schools, but are lacking the additional time and personnel such programs frequently demand. Although further research is necessary to validate the efficacy of the program, the preliminary evidence garnered by the present study suggests that a singlesession school-based program is feasible, acceptable, and is perceived to be useful, particularly with regard to students' understanding of stress management and future willingness to use stress management strategies. 
This is an Accepted Manuscript of an article published by Taylor \& Francis in 'Advances in School Mental Health Promotion' on 2015-11-30, available online: https://www.tandfonline.com/10.1080/1754730x.2015.1110494.

\section{References}

American Psychological Association. (2014). Stress in America 2014. Retrieved from https://www.apa. org/news/press/releases/stress/2013/stress-report.pdf

Amir, N., Weber, G., Beard, C., Bomyea, J., \& Taylor, C. T. (2008). The effect of a single-session attention modification program on response to a public-speaking challenge in socially anxious individuals. Journal of Abnormal Psychology, 117, 860-868. doi:10.1037/a0013445

Arnsten, A. F. T. (1998). Catecholamine modulation of prefrontal cortical cognitive function. Trends in Cognitive Sciences, 2, 436-447. doi:10.1016/S1364-6613(98)01240-6

Auerbach, R. P., Bigda-Peyton, J., Eberhart, N. K., Webb, C. A., \& Ho, M. H. R. (2011). Conceptualizing the prospective relationship between social support, stress, and depressive symptoms among adolescents. Journal of Abnormal Child Psychology, 39, 475-487. doi:10.1007/s10802-010-9479-X

Barrett, P. M. (2005). FRIENDS for life group leaders' manual for youth. Brisbane: Australian Academic Press. Barrett, P., \& Turner, C. (2001). Prevention of anxiety symptoms in primary school children: Preliminary results from a universal school-based trial. British Journal of Clinical Psychology, 40, 399-410.

doi:10.1348/014466501163887

Beck, A. T., Rush, A. J., Shaw, B. F., \& Emery, G. (1979). Cognitive therapy of depression. New York, NY: Guilford Press.

Beck, A. T., Emery, G., \& Greenberg, R. L. (1985). Anxiety disorders and phobias: A cognitive perspective. 
This is an Accepted Manuscript of an article published by Taylor \& Francis in 'Advances in School Mental Health Promotion' on 2015-11-30, available online: https://www.tandfonline.com/10.1080/1754730x.2015.1110494.

New York, NY: Basic Books.

Broderick, P. C., \& Metz, S. (2009). Learning to BREATHE: A pilot trial of a mindfulness curriculum for adolescents. Advances in School Mental Health Promotion, 2, 35-46. doi:10.1080/175473 0X.2009.9715696

Byrne, D. G., Davenport, S. C., \& Mazanov, J. (2007). Profiles of adolescent stress: The development of the adolescent stress questionnaire (ASQ). Journal of Adolescence, 30, 393-416. doi:10.1016/j. adolescence.2006.04.004

Cohen, S., Kamarck, T., \& Mermelstein, R. (1983). A global measure of perceived stress. Journal of Health and Social Behavior, 24, 385-396.

Cohen, S., Kessler, R. C., \& Underwood Gordon, L. (1995). Perceived stress scale. In S. Cohen, R. C. Kessler, \& L. Underwood Gordon (Eds.), Measuring stress: A guide for health and social scientists. New York, NY: Oxford Press.

Compas, B. E., Connor-Smith, J. K., Saltzman, H., Thomsen, A. H., \& Wadsworth, M. E. (2001). Coping with stress during childhood and adolescence: Problems, progress, and potential in theory and research. Psychological Bulletin, 127, 87-127. doi:10.1037/0033-2909.127.1.87

Danitz, S. B., \& Orsillo, S. M. (2014). The mindful way through the semester: An investigation of the effectiveness of an acceptance-based behavioral therapy program on psychological wellness in first-year students. Behavior Modification, 38, 549-566. doi:10.1177/0145445513520218

de Anda, D. (1998). The evaluation of a stress management program for middle school adolescents.

Child and Adolescent Social Work Journal, 15, 73-85. doi:10.1023/A:1022297521709 
This is an Accepted Manuscript of an article published by Taylor \& Francis in 'Advances in School Mental Health Promotion' on 2015-11-30, available online: https://www.tandfonline.com/10.1080/1754730x.2015.1110494.

de Anda, D., Darroch, P., Davidson, M., Gilly, J., \& Morejon, A. (1990). Stress management for pregnant adolescents and adolescent mothers: A pilot study. Child and Adolescent Social Work Journal, 7, 53-67. doi:10.1007/BF00757589

Eisenberg, N., Spinrad, T. L., \& Eggum, N. D. (2010). Emotion-related self-regulation and its relation to children's maladjustment. Annual Review of Clinical Psychology, 6, 495-525. doi:10.1146/annurev. clinpsy.121208.131208

Evans, S. W., \& Weist, M. D. (2004). Commentary: Implementing empirically supported treatments in the schools: What are we asking? Clinical Child and Family Psychology Review, 7, 263-267.

Fisher, P. H., Masia-Warner, C., \& Klein, R. G. (2004). Skills for social and academic success: A school-based intervention for social anxiety disorder in adolescents. Clinical Child and Family Psychology Review, 7, 241-249. doi:10.1007/s10567-004-6088-7

Folkman, S., \& Lazarus, R. S. (1980). An analysis of coping in a middle-aged community sample. Journal of Health and Social Behavior, 21, 219-239.

Forman, E. M., Herbert, J. D., Moitra, E., Yeomans, P. D., \& Geller, P. A. (2007). A randomized controlled effectiveness trial of acceptance and commitment therapy and cognitive therapy for anxiety and depression. Behavior Modification, 31, 772-799. doi:10.1177/01454455507302202

Fridrici, M., \& Lohaus, A. (2009). Stress-prevention in secondary schools: Online-versus face-to-facetraining. Health Education, 109, 299-313. doi:10.1108/09654280910970884

Frydenberg, E., \& Lewis, R. (2000). Teaching coping to adolescents: When and to whom? American Educational Research Journal, 37, 727-745. doi:10.3102/00028312037003727 
This is an Accepted Manuscript of an article published by Taylor \& Francis in 'Advances in School Mental Health Promotion' on 2015-11-30, available online: https://www.tandfonline.com/10.1080/1754730x.2015.1110494.

Galaif, E. R., Sussman, S., Chou, C. P., \& Wills, T. A. (2003). Longitudinal relations among depression, stress, and coping in high risk youth. Journal of Youth and Adolescence, 32, 243-258. doi:10.1023

\section{/A:1023028809718}

Hampel, P., Meier, M., \& Kümmel, U. (2008). School-based stress management training for adolescents: Longitudinal results from an experimental study. Journal of Youth and Adolescence, 37, 1009-1024. doi:10.1007/s10964-007-9204-4

Hampel, P., \& Petermann, F. (2003). Anti-stress-training für kinder [Anti-stress-training for children] (2nd ed.). Weinheim: BeltzPvU.

Hampel, P., \& Petermann, F. (2005). Age and gender effects on coping in children and adolescents.

Journal of Youth and Adolescence, 34, 73-83. doi:10.1007/s10964-005-3207-9

Hampel, P., \& Petermann, F. (2006). Perceived stress, coping, and adjustment in adolescents. Journal of Adolescent Health, 38, 409-415. doi:10.1016/j.jadohealth.2005.02.014

Hankin, B. L., Mermelstein, R., \& Roesch, L. (2007). Sex differences in adolescent depression: Stress exposure and reactivity models. Child Development, 78, 279-295. doi:10.1111/j.14678624.2007.00997.x

Hayes, S. C. (2004). Acceptance and commitment therapy, relational frame theory, and the third wave of behavioral and cognitive therapies. Behavior Therapy, 35, 639-665. doi:10.1016/S00057894(04)80013-3

Hofmann, S. G., \& Asmundson, G. J. (2008). Acceptance and mindfulness-based therapy: New wave or old hat? Clinical Psychology Review, 28, 1-16. doi:10.1016/j.cpr.2007.09.003 
This is an Accepted Manuscript of an article published by Taylor \& Francis in 'Advances in School Mental Health Promotion' on 2015-11-30, available online: https://www.tandfonline.com/10.1080/1754730x.2015.1110494.

Huberty, T. J. (2012). School-based interventions. In T. J. Huberty (Ed.), Anxiety and depression in children and adolescents (pp. 323-344). New York, NY: Springer.

Kabat-Zinn, J. (1990). Full catastrophe living: Using the wisdom of your body and mind to face stress, pain and illness. New York, NY: Delacourt.

Kendall, P. C. (Ed.). (2012). Child and adolescent therapy: Cognitive-behavioral procedures (4th ed.). New York, NY: Guilford Press.

Linehan, M. (1993). Cognitive behavioral treatment of borderline personality disorder. New York, NY: Guilford Press.

Lock, S., \& Barrett, P. M. (2003). A longitudinal study of developmental differences in universal preventive intervention for child anxiety. Behaviour Change, 20, 183-199. doi:10.1375/bech.20.4.183.29383 Lowry-Webster, H. M., Barrett, P. M., \& Dadds, M. R. (2001). A universal prevention trial of anxiety and

depressive symptomatology in childhood: Preliminary data from an Australian study. Behaviour Change, 18, 36-50. doi:10.1375/bech.18.1.36

McNamara, S. (2000). Stress in young people: What's new and what can we do? New York, NY: Continuum. Metz, S. M., Frank, J. L., Reibel, D., Cantrell, T., Sanders, R., \& Broderick, P. C. (2013). The effectiveness of the learning to BREATHE program on adolescent emotion regulation. Research in Human Development,

10, 252-272. doi:10.1080/15427609.2013.818488 
This is an Accepted Manuscript of an article published by Taylor \& Francis in 'Advances in School Mental Health Promotion' on 2015-11-30, available online: https://www.tandfonline.com/10.1080/1754730x.2015.1110494.

Moksnes, U. K., Byrne, D. G., Mazanov, J., \& Espnes, G. A. (2010). Adolescent stress: Evaluation of the factor structure of the Adolescent Stress Questionnaire (ASQ-N). Scandinavian Journal of Psychology, 51, 203-209. doi:10.1111/j.1467-9450.2009.00803.x

Nosaka, M., \& Okamura, H. (2015). A single session of an integrated yoga program as a stress management tool for school employees: Comparison of daily practice and nondaily practice of a yoga therapy program. The Journal of Alternative and Complementary Medicine, 21, 444-449. doi:10.1089/acm.2014.0289

Pincus, D. B., \& Friedman, A. G. (2004). Improving children's coping with everyday stress: Transporting treatment interventions to the school setting. Clinical Child and Family Psychology Review, 7, 223-240. doi:10.1007/s10567-004-6087-8

Rabin, B. S. (1999). Stress, immune function and health: The connection. New York, NY: Wiley.

Rachman, S. (1997). The evolution of cognitive behaviour therapy. In D. Clark, C. G. Fairburn, \& M. G. Gelder (Eds.), Science and practice of cognitive behavior therapy (pp. 1-26). Oxford: Oxford University Press.

Rew, L. (2005). Adolescent health: A multidisciplinary approach to theory, research, and intervention. Thousand Oaks, CA: Sage.

Rudolph, Karen D (2002). Gender differences in emotional responses to interpersonal stress during adolescence. Journal of Adolescent Health, 30, 3-13. doi:10.1016/S1054-139X(01)00383-4

Schmeelk-Cone, K. H., \& Zimmerman, M. A. (2003). A longitudinal analysis of stress in African American youth: Predictors and outcomes of stress trajectories. Journal of Youth and Adolescence, 32, 419-430. doi:10.1023/A:1025934301468 
This is an Accepted Manuscript of an article published by Taylor \& Francis in 'Advances in School Mental Health Promotion' on 2015-11-30, available online: https://www.tandfonline.com/10.1080/1754730x.2015.1110494.

Schonert-Reichl, K. A., \& Lawlor, M. S. (2010). The effects of a mindfulness-based education program on pre-and early adolescents' well-being and Social and emotional competence. Mindfulness, 1, 137-151. doi:10.1007/s12671-010-0011-8

Segal, Z. v., Williams, J. M. G., \& Teasdale, J. D. (2002). Mindfulness-based cognitive therapy for depression: A new approach to preventing relapse. New York, NY: Guilford.

Shapiro, A. J., \& Heath, N. L. (2013). @ S StressOFF strategies: A stress management program for teens. Montreal: Unpublished program and guide, Department of Educational and Counselling Psychology, McGill University.

Shimazu, A., Umanodan, R., \& Schaufeli, W. B. (2006). Effects of a brief worksite stress management program on coping skills, psychological distress and physical complaints: A controlled trial. International Archives of Occupational and Environmental Health, 80, 60-69. doi:10.1007/s00420- 006-0104-9

Suldo, S. M., Shaunessy, E., \& Hardesty, R. (2008). Relationships among stress, coping, and mental health in high-achieving high school students. Psychology in the Schools, 45, 273-290. doi:10.1002/ pits.20300

vøllestad, J., Nielsen, M. B., \& Nielsen, G. H. (2011). Mindfulness-and acceptance-based interventions for anxiety disorders: A systematic review and meta-analysis. British Journal of Clinical Psychology, 51, 239-260. doi:10.1111/j.2044-8260.2011.02024.x

Waaktaar, T., Borge Helmen, A. I., Fundingsrud, H. P., Christie, H. J., \& Torgersen, S. (2004). The role of stressful life events in the development of depressive symptoms in adolescence: A longitudinal study. Journal of Adolescence, 27, 153-163. doi:10.1016/j.adolescence.2003.09.006 
This is an Accepted Manuscript of an article published by Taylor \& Francis in 'Advances in School Mental Health Promotion' on 2015-11-30, available online: https://www.tandfonline.com/10.1080/1754730x.2015.1110494.

Washington, T. D. (2009). Psychological stress and anxiety in middle to late childhood and early adolescence: Manifestations and management. Journal of Pediatric Nursing, 24, 302-313. doi:10.1016/j.pedn.2008.04.011 
This is an Accepted Manuscript of an article published by Taylor \& Francis in 'Advances in School Mental Health Promotion' on 2015-11-30, available online: https://www.tandfonline.com/10.1080/1754730x.2015.1110494.

\section{Tables and Figures}

Table 1. Preprogram responses and scores.

\begin{tabular}{|c|c|c|c|c|c|c|c|c|}
\hline & \multicolumn{2}{|c|}{$\begin{array}{l}\text { Males } \\
(n=240)\end{array}$} & \multicolumn{3}{|c|}{ Females $(n=325)$} & \multicolumn{2}{|c|}{$\begin{array}{c}\text { Total } \\
(n=565)\end{array}$} & \multirow{2}{*}{$\begin{array}{c}\text { Effect } \\
\text { size }\end{array}$} \\
\hline & M & SD & $M$ & SD & $t$ & $M$ & SD & \\
\hline Knowledge about stress and stress managementa $^{a}$ & 1.15 & 0.68 & 1.19 & 0.65 & -0.64 & 1.18 & 0.66 & 0.05 \\
\hline $\begin{array}{l}\text { interest in knowing about stress and stress } \\
\text { management }{ }^{\mathrm{b}}\end{array}$ & 1.60 & 0.80 & $1.85^{\star *}$ & 0.72 & -3.89 & 1.74 & 0.76 & 0.33 \\
\hline $\begin{array}{l}\text { Frequency of using stress management } \\
\text { techniques }^{c}\end{array}$ & 1.37 & 0.86 & $1.87^{\star}$ & 0.79 & -7.04 & 1.66 & 0.85 & 0.60 \\
\hline
\end{tabular}

alikert-type 4-point scale ( 0 = nothing at all; 1 = A bit; 2 = Quite a bit; 3 = A lot).

b Iikert-type 4-point scale ( $0=$ not at all interested; 1 = A bit interested; 2 = Quite interested; 3 = very interested).

clikert-type 4-point scale ( 0 = never; 1 = Almost never; 2 = sometimes; 3 = very often).

${ }^{*} p<.05 ;{ }^{* *} p<.001$.

Table 2. Postprogram knowledge of stress, program satisfaction, and understanding and willingness to use specificstrategies.

\begin{tabular}{|c|c|c|c|c|c|c|c|c|}
\hline & \multicolumn{2}{|c|}{$\operatorname{Males}(n=240)$} & \multicolumn{3}{|c|}{ Females $(n=325)$} & \multicolumn{2}{|c|}{ Total $(n=565)$} & \multirow{2}{*}{$\begin{array}{c}\begin{array}{c}\text { Effect } \\
\text { size }\end{array} \\
d\end{array}$} \\
\hline & $M$ & SD & $M$ & SD & $t$ & M & SD & \\
\hline $\begin{array}{l}\text { Amountstudentslearnedaboutstress } \\
\text { management after workshop }\end{array}$ & 2.11 & 0.70 & 2.16 & 0.63 & -0.85 & 2.14 & 0.66 & 0.07 \\
\hline $\begin{array}{l}\text { Program satisfaction } \\
\text { Understanding of stress management } \\
\text { strategies }^{\mathrm{a}}\end{array}$ & 3.15 & 0.69 & 3.18 & 0.62 & -0.46 & 3.16 & 0.65 & 0.04 \\
\hline thought challenge & 2.29 & 0.67 & $2.46^{*}$ & 0.58 & -3.13 & 2.39 & 0.63 & 0.28 \\
\hline Muscle relaxation & 2.63 & 0.53 & $2.74^{*}$ & 0.49 & 2.17 & 2.69 & 0.51 & 0.20 \\
\hline self-observer & 2.29 & 0.70 & 2.40 & 0.68 & -1.76 & 2.35 & 0.69 & 0.15 \\
\hline support and better choices & 2.37 & 0.66 & $2.56^{* *}$ & 0.56 & -3.35 & 2.38 & 0.74 & 0.31 \\
\hline \multicolumn{9}{|l|}{$\begin{array}{l}\text { Willingness to use stress management } \\
\text { strategies }^{\text {a }}\end{array}$} \\
\hline thought challenge & 2.06 & 0.76 & 2.13 & 0.79 & -0.92 & 2.10 & 0.78 & 0.08 \\
\hline Muscle relaxation & 2.41 & 0.85 & $2.58^{*}$ & 0.92 & -2.08 & 2.51 & 0.90 & 0.18 \\
\hline self-observer & 2.00 & 0.82 & $2.19^{*}$ & 0.85 & -2.41 & 2.11 & 0.84 & 0.21 \\
\hline support and better choices & 2.17 & 0.81 & $2.45^{* *}$ & 0.88 & -3.69 & 2.34 & 0.87 & 0.33 \\
\hline
\end{tabular}

a ikert-type 4-point scale ( 0 = never; 1 = Almost never; 2 = sometimes; 3 = very often).

${ }^{*} p<.05 ;{ }^{* *} p<.001$. 